\title{
El documental chileno de post-dictadura y la dimensión performática del lenguaje audiovisual en el conflicto político
}

\section{The post-dictatorship Chilean documentary and the performative dimension of the audiovisual language in the political conflict}

\author{
TIPO DE TRABAJO: Comunicación. \\ PALABRAS CLAVE \\ Documental, dictadura, narrativa documental, performance.
}

KEY WORDS

Documentary, dictatorship, documentary narrative, performance.

RESUMEN

Uno de los mayores acontecimientos sociales y políticos en la historia reciente de Chile es la dictadura cívico-militar extendida entre los años 1973 y 1989. Frente a este acontecimiento, múltiples producciones culturales pueden servir como herramientas críticas para acercarnos al pasado, y una de ellas es el cine documental. Específicamente el documental de post-dictadura que, como sugiere Antonio Traverso, no refiere a una determinada historiografía, sino a aquellos filmes que guardan una relación crítica con el pasado. Bajo este parámetro, podemos encontrar recientes producciones como El Pacto de Adriana (2017) de Lissette Orozco y El Color del Camaleón (2017) de Andrés Lübbert. Ambos, a través de un relato autobiográfico y familiar, indagan en los relatos de perpetradores. Por un lado, Lissette Orozco descubre que su querida tía Chany trabajó para los servicios secretos chilenos (DINA), y está actualmente acusada de haber cometido crímenes de lesa humanidad; $y$, por otro lado, Andrés Lübbert decide buscar los orígenes del trauma de su padre, quien fue capturado por la DINA y sometido a entrenamiento militar en contra de su voluntad.

A través de ambas películas, es posible ver cómo la enunciación en primera persona y la autobiografía, son conceptos que se entrelazan con la historia política de un país. En un diálogo constante con el pasado, ambos directores establecen estrategias narrativas performativas para acercase a la confrontación, reconciliación o reparación. Entonces surgen preguntas acerca de la subjetividad y de la autobiografía como un espacio político en que se pueda trascender el yo. En este trabajo, buscaremos dilucidar en qué sentido podría la performatividad de la narración documental otorgar un carácter político al lenguaje audiovisual.

\section{ABSTRACT}

One of the most important social and political events in the recent history of Chile is the civil-military dictatorship extended between 1973 and 1989. Faced this event, different kinds of cultural productions can serve as critical tools to approach the past, and one of them It is documentary cinema. Specifically, the post-dictatorship documentary cinema as Antonio Traverso suggests, does not refer to a specific historiography but to those films that have a critical relationship with the past. Under this parameter we can find recent productions such as El Pacto de Adriana (2017) by Lissette Orozco and El Color del Camaleón (2017) by Andrés Lübbert. Both documentaries through an autobiographical and family story investigate the stories of perpetrators. On one hand, Lissette Orozco discovers that her beloved Aunt Chany worked for the Chilean secret services (DINA), and is currently accused of having committed crimes against humanity. And on the other hand, Andrés Lübbert decides to look for the origins of the trauma of his father, who was kidnapped by the DINA and subjected to military training.

Through both films it is possible to see how the enunciation in the first person and the autobiography are concepts that are intertwined with the political history of a country. In a constant dialogue with the past both directors establish performative narrative 
strategies to approach confrontation, reconciliation or reparation. Then questions arise about subjectivity and autobiography as a political space in which the self can be transcended. In this work, we will seek to elucidate in what sense the performativity of the documentary narrative could grant a political character to the audiovisual language.

\section{INTRODUCCIÓN}

La dictadura de Augusto Pinochet, extendida entre 1973 y 1989, es uno de los hitos que ha marcado con mayor énfasis la historia reciente de Chile. Con ello, distintas producciones culturales se han posicionado como agentes críticos, que sirven como herramientas para el cuestionamiento y la construcción de la memoria del país. El cine documental ha tenido un lugar protagónico en este sentido, no solo como un vasto registro de imágenes y testimonios de la violencia vivida, sino también como un escenario desde donde podemos pensar de manera crítica el pasado.

El cine documental de post-dictadura, hace referencia a un tipo de narrativa que autores como Antonio Traverso, proponen analizar desde una perspectiva no necesariamente histórica y secuencial con la dictadura como punto de referencia. "...the notion of postdictatorship names not a delimited historiography but the politics of an unfolding critical process of cultural memory within which existing and new screen works acquire or lose significance in relation to the ongoing ideological contestation of the past" (Traverso, 2018a). El cine de post-dictadura sería aquel que nos permite establecer un diálogo con el pasado, que nos entrega herramientas o problemas a través de los cuales re-revisar el pasado. En este sentido, directores como Patricio Guzmán han tenido gran relevancia a la hora de rescatar la memoria estableciendo un diálogo con el pasado. La batalla de Chile, una trilogía documental filmada entre 1976 y 1979, se estrena en Chile 18 años después de su filmación, esto nos habla de lo conflictivo que es ese diálogo en la sociedad chilena; así también lo explica el propio director en una entrevista realizada por la televisión argentina ${ }^{1}$.

En 1994 se estrena el documental dirigido por Carmen Castillo La flaca Alejandra, proponiendo una narración centrada en el testimonio de Alejandra Merino, ex militante del MIR (Movimiento de Izquierda Revolucionario), quien fue capturada, torturada y extorsionada por la DINA; cuya experiencia acabó doblegando su posición convirtiéndose en colaboradora del régimen. Se piensa que su colaboración con los servicios secretos fue instrumental y fundamental para la localización de la propia directora Carmen Castillo y de su pareja Miguel Enríquez, ambos militantes del MIR. Esto significó el allanamiento de su casa, la muerte de Miguel y el ingreso de Carmen en el hospital gravemente herida estando embarazada. Después de años de exilio en Francia, Carmen Castillo vuelve a Chile para filmar el documental, abriendo un espacio controversial de discusión y reflexión al proponer el testimonio de una figura poco usual como protagonista, y mirar a través de ella el pasado. Es posible situar este documental como un referente para nuevas producciones que han visto la pantalla el último tiempo, como lo son: El color del camaleón dirigido por Andrés Lübbert y El pacto de Adriana dirigido por Lissette Orozco, estrenados en 2017. Ambos han tenido un reconocimiento tanto nacional como internacional y han abierto un espacio de reflexión en torno a la experiencia de las nuevas generaciones que dialogan con el pasado. Considerados como "directores de segunda generación" (Traverso, 2018b), nos proponen un acercamiento crítico al pasado desde la perspectiva de quienes formaron parte del aparato represor y que, además, forman parte de su círculo familiar y afectivo íntimo. Por un lado, Lissette Orozco descubre que su querida tía Chany trabajó para los servicios secretos chilenos (DINA), y está actualmente acusada de haber cometido crímenes de lesa humanidad; y, por otro lado, Andrés Lübbert decide buscar los orígenes del trauma de su padre, quien fue capturado por la DINA y sometido a entrenamiento militar en contra de su voluntad. Si bien estos documentales se estructuran en función de la figura de la tía y el padre, respectivamente, ambos responden a una narración en primera persona de parte de los directores. Son historias presentadas desde la intimidad, desde la autobiografía. En este sentido, nuevamente la directora Carmen Castillo puede ser un referente con su documental Calle Santa Fe (2007) frente al cual Nelly Richard comenta lo siguiente: "el giro biográfico de su exploración de una memoria personal se abre a la dimensión colectiva de una valiente reflexión sobre las implicancias de haber sido militante mujer de un partido político de extrema izquierda en tiempos de ferviente compromiso con la lucha revolucionaria"(Richard, 2010, p. 139). Es decir, se identifica un giro biográfico a la vez que colectivo, posicionando al relato en primera persona como el lugar desde dónde explorar el pasado. Tanto El pacto de Adriana como El Color del Camaleón comparten esta condición, que desde su experiencia como "directores de segunda generación", toman el desafío de cuestionar sus relaciones afectivas y familiares para mirar el pasado desde una perspectiva crítica.

\footnotetext{
${ }^{1}$ Ver en: $\underline{\text { https://www.patricioguzman.com/es/peliculas/6)-memoria-obstinada }}$
} 


\section{METODOLOGÍA}

En este trabajo nos proponemos estudiar algunos de los elementos que estructuran las narraciones de estos dos documentales de post-dictadura, identificando dos elementos fundamentales desde donde comenzaremos la reflexión: primero, la narración en primera persona y el giro subjetivo de estas narraciones; y segundo, la problemática relación íntima que guardan los directores con quienes perpetraron crímenes durante el régimen militar, o bien, mantuvieron una relación cercana con el aparato represor. Ambas líneas reflexivas nos ayudarán a establecer una relación entre el lenguaje audiovisual y la dimensión política del film.

\section{LA NARRACIÓN EN PRIMERA PERSONA}

Dentro de su libro Tiempo Pasado. Cultura de la memoria y giro subjetivo. Una discusión (2013), Beatriz Sarlo sitúa el giro subjetivo de la narración como un efecto proveniente de la ambición por entender el pasado desde su propia lógica, es decir, desde la idea de que existe un solo relato del pasado y que éste puede ser enunciado en primera persona. Frente a esto es que, desde mediados del siglo XIX, la literatura aplica diversos "modos de subjetivación de lo narrado". La autora explica que "la actual tendencia académica y del mercado de bienes simbólicos que se propone reconstruir la textura de la vida y la verdad albergadas en la rememoración de la experiencia, la revaloración de la primera persona como punto de vista, la reivindicación de una dimensión subjetiva, que hoy se expande sobre los estudios del pasado y los estudios culturales del presente, no resultan sorprendentes" (Sarlo, 2013, p. 20). Esto se debe a que nos encontramos en un contexto donde las condiciones ideológicas acompañan dicha valoración del yo.

Por otro lado, el posicionamiento del testimonio dentro del cine documental tanto en Argentina como en Chile, es un elemento que se hizo necesario para comprender los daños de la violencia de los regímenes dictatoriales. En ese sentido, la autora también señala que "la historia oral y el testimonio han devuelto la confianza a esa primera persona que narra su vida (privada, pública, afectiva, política), para conservar el recuerdo o para reparar una identidad lastimada" (op. cit, p.21). En una dirección similar, Nelly Richard se refiere al testimonio como "actos de memoria que tienen la virtud de rememorar aquello que los operativos de la destrucción hubieran dejado sin memoria, si no fuera por aquellas voces rescatadas del infierno que, en su condición de víctimas, constatan la violencia de lo extremo y la convierten así en prueba irrefutable de lo consumado" (Richard, 2010, p. 78). Es por esto, que el elemento testimonial dentro del cine documental de post-dictadura, no es solo un recurso propio de la narrativa documental o un elemento aislado, posee un contexto histórico y político desde el cual debemos abordarlo.

Tanto en El Color del Camaleón como en El Pacto de Adriana, el testimonio es un elemento importante en la narración. Adriana Rivas, investigada por secuestro, desaparición de personas y participación en torturas, es quien ocupa el lugar testimonial dentro de la película de Orozco-lugar que históricamente ha pertenecido a la víctima-, lo que la ubica en un lugar de enunciación privilegiado. Y, por otro lado, Jorge Lübbert, instruido por la DINA y entrenado para ser asesino, se ve en reiteradas ocasiones impedido para pronunciar su testimonio en el film. Ambos documentales nos presentan figuras poco usuales en la pantalla, lo que abre un espacio de interés crítico con respecto a estos personajes y su relación con la historia, además de su vinculación familiar con los directores.

Sin embargo, por muy predominante que sean los testimonios dentro de estos documentales, finalmente son películas narradas en primera persona por los directores. Lissette Orozco se enfrenta al testimonio de su tía, testimonio en un principio inapelable, pero que se atreve a cuestionar y finalmente confrontar, pagando un precio ético y político al quebrar su relación familiar. Andrés Lübbert se enfrenta a la incapacidad de su padre para testimoniar y debe lidiar con la duda de no saber si fue o no un asesino; finalmente, descansando en el conocimiento de que su padre es un tipo de víctima poco común, y no un perpetrador. Andrés entonces enuncia el testimonio por medio de un actor. Es decir, nos encontramos frente a voces en primera persona -las de los directores-, que a su vez se enfrentan a testimonios en primera persona -los testimonios de sus familiares.

De esta manera, la subjetividad es el elemento predominante dentro de estos documentales, es el objeto de estudio al mismo tiempo que el lugar de enunciación. Son narraciones que no pretenden validar un discurso o derribarlo, tampoco pretenden ser investigaciones judiciales; si bien consideran varios de esos elementos, se proponen otro objetivo, más ligado a documentar la respuesta de los directores frente a la interpelación de la historia política que inunda sus relaciones familiares. Las relaciones familiares al inicio de los documentales son completamente diferentes de lo que podemos apreciar al final, es decir, asistimos a una transformación de facto. $Y$ es en este punto donde los estudios de performance se convierten en una herramienta de análisis. 


\section{TRANSFORMACIÓN DESDE LA SUBJETIVIDAD}

Como lo explica Diana Taylor en el libro Estudios avanzados de performance (2011), los conceptos performático y performativo, poseen distintas definiciones, algunas relativas a los estudios de las artes visuales, del teatro, de la sociología o la lingüística. Donde lo performático define una acción, rito o práctica. Diana Taylor utiliza la protesta social como ejemplo de un acto performático. Por otro lado, lo performativo, más cercano a los estudios lingüísticos, hace referencia a una cualidad del discurso, a un lenguaje que hace en su propia enunciación. En el caso de la narración documental, por ejemplo, podríamos pensar en El Pacto de Adriana como una acción de confrontación y denuncia, y en El Color del camaleón, como una acción de reparación.

Como vimos anteriormente, la directora de El Pacto de Adriana decide tomar como punto de partida el testimonio de su tía, quien niega rotundamente su participación en los crímenes de los que se le acusa y afirma que se trata de una equivocación de la que está siendo víctima. Así es como la directora comienza su investigación, y en la medida que ésta se desarrolla, comienza también su transformación. Las filmaciones del testimonio de Adriana son presentadas de dos maneras: primero, la filmación directa u original; y segundo, las revisiones que Lissette hace de las imágenes proyectadas en la pared a gran escala. Esta segunda operación, es un recurso que se repite tres veces a lo largo de la película y nos detendremos en él un momento. El desarrollo del documental es a la vez una transformación de la relación íntima entre tía y sobrina, en la que Lissette comienza a cuestionar el testimonio, ese cuestionamiento es reflejado de manera plástica. Las escenas en que la directora se enfrenta a las imágenes son un recurso plástico que posee una dimensión performática. Lissette genera un rito confrontacional con las imágenes, viviendo con ello su propia transformación. Esta acción constituye un acto performático dentro de la narración.

En el capítulo "Usted está aquí": El ADN del performance (Taylor, 2011), considerando los actos públicos de protesta y denuncia por violaciones a los derechos humanos llevados a cabo en Argentina durante la dictadura cívico-militar, Taylor propone dos conceptos fundamentales para articular su teoría: archivo y repertorio. Que corresponderían a elementos que constituyen o alimentan las diferentes acciones a través de las que se presenta y representa un cambio social; siendo también transmisores de la memoria traumática. Las fotos de los desaparecidos ${ }^{2}$, por ejemplo, llevadas al espacio público se activaron como performance, haciendo visible la desaparición. Aunque parecieran formar parte de un archivo, estas fotografías serían parte de un repertorio performático, y el archivo estaría constituido por investigaciones, pruebas judiciales, demandas legales e históricas. Otro elemento fundamental que Taylor considera para estudiar estos actos como performances es el "en vivo". La dimensión corporal vivencial de los actos llevados a cabos, lo que no solo apela a un cambio político de facto -considerando que los agentes que desarrollan estas performances son entidades organizadas que al mismo tiempo llevan a cabo demandas judiciales exigiendo una justicia institucional para las víctimas-, sino que también considera un cambio experiencial personal, que ella misma vivió al asistir a un escrache $e^{3}$ en Buenos Aires.

"Así, el performance opera para transmitir recuerdos traumáticos, a partir de y al transformar un archivo y un repertorio compartidos de imágenes culturales. Estos performances de protesta funcionan como "síntoma" de la historia (es decir, la exteriorizan), parte integral del trauma. También declaran una distancia crítica para elaborar un reclamo, al afirmar lazos y conexiones mientras denuncian violaciones a los contratos sociales" (Taylor, 2011).

Volviendo al acto performático que Orozco realiza en su documental, podríamos considerar el testimonio como ese repertorio señalado por Taylor, siendo esta acción la manera de enunciar una posición ética y política frente a su tía; fundamentada por el archivo generado en su investigación paralela. Por otro lado, es fundamental destacar todas las imágenes y material de archivo que forman parte de la investigación documental; la directora dota de historicidad y contexto político su proceso. Utilizando imágenes de la funa que se llevó a cabo frente a la casa de Adriana en Australia, o aludiendo al reportaje y entrevista realizados por la televisión australiana respecto del caso de su tía, justo durante el periodo de rodaje del documental. Todos estos acontecimientos que marcan el desarrollo del documental nos hablan de la conexión de Orozco a un contexto histórico y político determinado, que es el que confronta su subjetividad y la lleva a generar un cambio a nivel efectivo familiar. En otras palabras, la narración documental constituye un acto de confrontación y denuncia, allí se encontraría su dimensión performativa, en el acto. . Una confrontación personal devenida social y pública a través del cine, con lo cual además genera una experiencia colectiva que invita a un diálogo crítico con el pasado. Es decir, desde la primera persona y la biografía, se genera una conexión con el conflicto político público, frente al cual se toma una decisión política. El pacto de Adriana no es un documental político por su conexión con la dictadura militar, lo es porque conlleva una responsabilidad, decisión y acto político: la confrontación, la ruptura y la denuncia.

Pensemos ahora en El Color del Camaleón. Como dijimos anteriormente, en este documental el director se enfrenta a su padre traumatizado por su pasado y juntos emprenden un viaje de reconstrucción. En reiteradas ocasiones Andrés intenta hablar con su

\footnotetext{
${ }^{2}$ Tanto en Argentina como en Chile, se llevaron a cabo diferentes acciones públicas que instalaron en las calles las imágenes de los detenidos desaparecidos. Siendo en Argentina altamente reconocidas y difundidas las caminatas llevadas a cabo por las Abuelas y las Madres en la Plaza de Mayo.

${ }^{3}$ Escrache es el nombre que lleva la acción pública de denuncia frente a quienes fueron perpetradores de crímenes durante la dictadura y que aún no son juzgados. Similar es en Chile la conocida Funa, igualmente llevada a cabo por comisiones o entidades organizadas. Ver más en: http://comisionfuna.org/ http://www.hijos-capital.org.ar/
} 
padre y obtener un testimonio concreto de sus vivencias en relación a su entrenamiento en la DINA, pero Jorge es incapaz de articular un discurso coherente. Nelly Richard, analizando algunos relatos testimoniales explica: "La falta de voz, de la voz como vehículo expresivo de una subjetividad hablante, somatiza la destrucción de una persona que la experiencia límite ha convertido en alguien ya incapaz de pronunciar sonido, de testimoniar de sí misma como fuente de sentido" (Richard, 2010). Es decir, la incapacidad de enunciar un discurso, por parte del padre es el síntoma de su trauma. Frente a esto, el director decide generar una acción, que al igual que Lissette, acompañará el proceso documental. Esta acción consiste en grabar una locución del testimonio escrito de su padre, llevada a cabo por un actor contratado que recibe instrucciones del propio padre. El documental muestra las escenas en el estudio de grabación en que el padre indica velocidad y volumen de voz al actor, reparando, a través de la enunciación, su testimonio. Esta acción sería un acto performático, cuya realización significó una recomposición de lazos familiares, a la vez que identitarios y subjetivos. En este caso, el testimonio escrito formaría parte de un repertorio que al enunciarse alcanza una dimensión performática. Por otro lado, el archivo estaría conformado por la investigación paralela, que también dota de historicidad y contexto político a la película; padre e hijo asisten a diferentes manifestaciones en Santiago de Chile, creando una experiencia común de reparación entre ambos. Taylor también concluye "Así, el ADN del performance, como la investigación biológica en curso, puede expandir, más que limitar, nuestro sentido de conectividad: todos compartimos una buena parte de materiales genéticos, culturales, políticos y socioeconómicos. 'Usted está aquî́ señala no solo el espacio de performance, sino también el ambiente colectivo del trauma que toca y afecta a todos. Estamos, todos, aquí" (Taylor, 2011)

\section{CONCLUSIONES}

Con la idea de establecer un carácter performático y performativo de estos documentales, lo que hacemos es intentar develar la dimensión política de los mismos. No en su conexión directa temática con la dictadura militar, sino por su posibilidad de generar cambios. La crítica al giro subjetivo de la narración funciona como motor de arranque que nos desafía a validar esta enunciación como un espacio colectivo; a establecer el puente entre la biografía personal y el conflicto político público. Si bien estos documentales son narraciones íntimas en primera persona, se abren hacia una intención y compromiso públicos. El pacto de Adriana ha recibido 18 premios en distintas partes del mundo, desatando junto a El Color del Camaleón, proyectado en más de cuarenta salas a nivel mundial, un interés crítico frente a la figura del perpetrador dentro del cine documental chileno. Estos documentales están dotados de una intencionalidad política, expresada por una narración documental performativa.

\section{FUENTES REFERENCIALES}

Castillo, C. (2007). Calle Santa Fe. [Documental; 167 minutos]. Chile-Francia: Les Films d'Ici / Les Films de la Passerelle / Institut National de l'Audiovisuel / Parox / Love Streams Productions.

Castillo, C. y Girard, G. (1994). La flaca Alejandra. [Documental; 57 minutos]. Chile: Ina / France 3 / Channel 4.

Lübbert, A. (2017). El color del camaleón. [Documental; 87 minutos]. Chile-Bélgica: Blume Producciones.

Orozco, L. (2017). El pacto de Adriana. [Documental; 96 minutos]. Chile: Salmón Producciones / Storyboard Media / Ursus Films / Carnada Film.

Richard, N. (2010). Crítica de la memoria (1990-2010). Santiago: Ediciones Universidad Diego Portales.

Sarlo, B. (2013). Tiempo pasado. Cultura de la memoria y giro subjetivo. Una discusión. Editorial Universidad de Talca.

Taylor, D. (2003). The archive and the repertorie. Performing cultural memory in the Americas. Duke University Press.

Taylor, D. (2011). "Usted está aquí": el ADN del performance. In Estudios avanzados de performance. México: Fondo de Cultura Económica.

Taylor, D., y Fuentes, M. (2011). Estudios avanzados de performance. México: Fondo de Cultura Económica.

Traverso, A. (2018a). Excavating La Moneda: cinematic memory and post-dictatorship documentary in Chile. Social Identities, O(0), 117. https://doi.org/10.1080/13504630.2018.1514168

Traverso, A. (2018b). Post-Dictatorship Documentary in Chile: Conversations with Three Second-Generation Film Directors. Humanities, 7(1), 8. https://doi.org/10.3390/h7010008 